\title{
Sudden Death in End Stage Renal Disease: Comparing Hemodialysis versus Peritoneal Dialysis
}

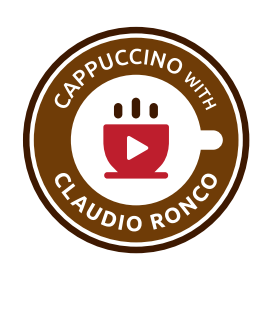

\author{
Simonetta Genovesi ${ }^{a, c}$ Luca Porcu $^{b}$ Maria Carmen Luise ${ }^{c}$ Hilary Riva $^{c}$ \\ Elisa Nava ${ }^{c}$ Gina Contaldo ${ }^{c}$ Andrea Stella ${ }^{a}$ Claudio Pozzi $^{d}$ Patrizia Ondei $^{\text {h }}$ \\ Claudio Minoretti ${ }^{i}$ Maurizio Gallieni ${ }^{\mathrm{e}}$ Giuseppe Pontoriero ${ }^{j}$ Ferruccio Conte $^{k}$ \\ Valter Torri $^{b}$ Silvio Bertoli ${ }^{f} \quad$ Antonio Vincenti ${ }^{g}$ \\ ${ }^{a}$ Nephrology Unit, San Gerardo Hospital, Monza, ${ }^{b}$ Methodology for Clinical Research Laboratory, \\ Oncology Department, IRCCS - Istituto di Ricerche Farmacologiche Mario Negri, 'Department Medicine \\ and Surgery, University of Milan Bicocca, dNephrology Unit, Bassini Hospital, Cinisello Balsamo, e Nephrology \\ Unit, San Carlo Borromeo Hospital, ${ }^{\mathrm{f}} \mathrm{Nephrology}$ Unit, and ${ }^{\mathrm{g}}$ Electrophysiology IRCCS Multimedica, \\ Sesto S. Giovanni, Milan, hNephrology Unit, Ospedali Riuniti Hospital, Bergamo, 'Nephrology Unit, Sant'Anna \\ Hospital, Como, j Nephrology Unit, Alessandro Manzoni Hospital, Lecco, and kNephrology Unit, Uboldo Hospital, \\ Cernusco sul Naviglio, Italy
}

\section{Keywords}

Hemodialysis · Mortality · Peritoneal dialysis · Regression models $\cdot$ Sudden death

\begin{abstract}
Background/Aims: This study aimed to evaluate total and sudden death (SD) in a cohort of dialysis patients, comparing hemodialysis (HD) vs. peritoneal dialysis (PD). Methods: This is a multicenter retrospective cohort study. Results: Deaths were 626 out of 1,823 in HD and 62 of 249 in PD patients. HD patients had a greater number of comorbidities $(p<0.05)$. PD patients had a lower risk of death than HD patients $(p<$ 0.001); however, the advantage decreased with time ( $p<$
\end{abstract}

0.001). Mortality predictors were left ventricular ejection fraction (LVEF) $\leq 35 \%$, older age, ischemic heart disease, diabetes mellitus, previous stroke, and atrial fibrillation ( $p<$ 0.03). SDs were 84:71 in HD and 13 in PD population (12.1 and $22.8 \%$ of all causes of death, respectively). A non-significant risk of SD among PD compared to HD patients was detected. SD predictors were older age, ischemic heart disease, and LVEF $\leq 35 \%$ ( $p<0.05)$. Conclusions: HD patients showed a greater presence of comorbidities and reduced survival compared to PD patients; however, the incidence of SD does not differ in the 2 populations.

Video Journal Club "Cappuccino with Claudio Ronco" at http://www.karger.com/?doi=464347.

() 2017 S. Karger AG, Basel

\section{KARGER}

(c) 2017 S. Karger AG, Basel

E-Mail karger@karger.com

www.karger.com/bpu
Simonetta Genovesi

Department of Medicine and Surgery

University of Milano Bicocca

Via Cadore 48, IT-20900 Monza (Italy)

E-Mail simonetta.genovesi@unimib.it 


\section{Introduction}

Cardiovascular disease is the leading cause of death in dialysis patients and sudden death (SD) represents a significant proportion of overall mortality in both hemodialysis (HD) and peritoneal dialysis (PD) patients. SD accounts for about $37.0 \%$ of all causes of death in patients with end stage renal disease (ESRD) and for $65.0 \%$ of cardiovascular deaths. The rate of cardiac arrest is $7.3 \%$ in HD and 6.0\% in PD patients [1]. There is evidence showing that left ventricular ejection fraction (LVEF) is the best predictor of total and sudden mortality in patients with cardiac disease, but without ESRD [2-4]. The factors associated with SD in patients undergoing dialysis are not very clear. It was shown that the high incidence of SD in HD patients could be partly explained by the rapid changes of plasma electrolytes related to the intermittent nature of this dialysis technique $[5,6]$. However, in PD patients, factors that can cause SD, despite continuous treatment, are not yet clear and few studies were carried out on this topic. Moreover, there are no data comparing the incidence of SD in HD patients with those undergoing PD.

In the last few years, several studies comparing the risk of total mortality in HD patients and patients on PD were performed. Almost all these studies showed a better survival during the first period from the start of dialysis in PD than in HD patients, but it is unclear whether the dialysis modality is associated with greater long-term survival [7-12].

The purpose of the present study is to assess, in a population of ESRD patients, the relationship between the different dialysis modality (HD vs. PD) and overall and sudden mortality and to identify predictors of outcomes for each dialysis modality.

\section{Methods}

In this Italian multicenter retrospective study, all dialysis patients (undergoing HD or PD) referred to 7 dialysis centers of Lombardy, alive on the January 1, 2010, or starting dialysis between January 1, 2010, and January 31, 2013 (recruitment time), were enrolled and their clinical charts were revised. Patients were considered eligible for the study only if an echocardiogram with a measured value of LVEF was available, either obtained within 6 months before recruitment if alive, or 6 months before death if deceased. Information on the presence of the following comorbidities was collected: ischemic cardiac disease, diabetes mellitus, previous stroke, and atrial fibrillation. Death causes were derived from medical records. The presence of an implanted cardioverter defibrillator (ICD) was also considered. SD was defined as spontaneous death preceded by a sudden loss of consciousness within $1 \mathrm{~h}$ after onset of acute symptoms, even in the presence of pre-existing heart disease, but with unexpected timing and mode. Nephrolo- gists or relatives were interviewed to confirm all cases of SD. Procedures were performed according to the Helsinki declaration for ethics treatment of human subjects and approved by the local Ethical Committee.

\section{Statistical Analysis}

Study end points were the following:

a. Overall survival defined as the time from the start of dialysis to the time of death from any cause;

b. Cause of death;

c. Cause-specific survival defined as the time from the start of dialysis to the time of SD or other cause.

Survival data of patients starting dialysis before the January 1, 2010 , and alive on the January 1, 2010, were left-truncated [13]. In other terms, these patients were not considered at risk of death during the interval time between the beginning of dialysis and January 1, 2010 (i.e., truncation period).

Overall survival distribution was estimated by the product-limit method. A linear time by treatment interaction term was introduced in a Cox regression model to demonstrate formally the curvature over time of the relative hazard function. The average hazard of death per unit time (i.e., each year following dialysis start) was estimated. A fixed-effects meta-regression was fitted to the point and standard error estimate of the average hazard of death per unit time. A meta-regression forest plot was used to summarize meta-regression results. The Cox regression model was used to evaluate predictors of overall survival and test their interaction with treatment.

In order to estimate the statistical association between the 2 cohorts of patients (i.e., HD and PD patients) and the specific cause of death (i.e., SD) and to identify patient characteristics statistically associated to the specific cause of death, a survival analysis in the presence of competing risks was performed. The Fine and Gray regression model was used to estimate the cause-specific hazards ratio $\left(\mathrm{HR}_{\mathrm{cpRisk}}\right)$.

In the Cox multivariable and Fine and Gray regression models, ICD implantation was considered a time-varying treatment.

Survival status was updated on the January 31, 2014. Median follow-up and its interquartile range (IQR) were estimated with the reverse Kaplan-Meier method [14]. The completeness index (C) [15] was used in order to quantify the completeness of followup at the update of survival status.

Baseline covariate distributions were summarized using descriptive statistics (median and range for continuous variables, and absolute and percentage frequencies for categorical variables). The logistic regression model was used to detect imbalances between baseline covariate distributions.

Statistical analysis was performed using Stata software version 12.1 (StataCorp. 2011; Stata Statistical Software, Release 12; StataCorp LP, College Station, TX, USA).

See online supplementary material (see www.karger.com/ doi/10.1159/000464347) for extended statistical analysis.

\section{Results}

Table 1 shows the characteristics of the studypopulation, 249 of 2,072 (12.0\%) patients were on PD. There were no significant differences in the prevalence of comorbidities 
Table 1. Characteristics of the study population

\begin{tabular}{|c|c|c|c|c|}
\hline & \multicolumn{2}{|l|}{ Patients } & \multicolumn{2}{|c|}{ Statistical association } \\
\hline & $\mathrm{HD}$ & $\mathrm{PD}$ & $\mathrm{OR}^{\S}(95 \% \mathrm{CI})$ & $p$ value \\
\hline \multicolumn{5}{|l|}{ Age at dialysis start, years } \\
\hline$n$ & 1,823 & 249 & $1.05(0.96-1.15)$ & 0.25 \\
\hline Median & 68.6 & 67.5 & & \\
\hline Range & $12.9-94.4$ & $23.2-87.1$ & & \\
\hline \multicolumn{5}{|l|}{ Gender, $n(\%)$} \\
\hline Female & $681(37.4)$ & $95(38.2)$ & 1 & 0.81 \\
\hline Male & $1,142(62.6)$ & $154(61.8)$ & $1.03(0.79-1.36)$ & \\
\hline \multicolumn{5}{|c|}{ Left ventricular ejection fraction, $n(\%)$} \\
\hline$<35 \%$ & $113(6.2)$ & $21(8.4)$ & 1 & 0.18 \\
\hline$>35 \%$ & $1,710(93.8)$ & $228(91.6)$ & $1.39(0.86-2.27)$ & \\
\hline \multicolumn{5}{|l|}{ Ischemic heart disease, $n(\%)$} \\
\hline No & $1,182(64.8)$ & $167(67.1)$ & 1 & 0.49 \\
\hline Yes & $641(35.2)$ & $82(32.9)$ & $1.10(0.83-1.46)$ & \\
\hline \multicolumn{5}{|l|}{ Diabetes mellitus, $n(\%)$} \\
\hline No & $1,325(72.7)$ & $189(75.9)$ & 1 & 0.28 \\
\hline Yes & $498(27.3)$ & $60(24.1)$ & $1.18(0.87-1.61)$ & \\
\hline \multicolumn{5}{|l|}{ Previous ischemic stroke, $n(\%)$} \\
\hline No & $1,585(86.9)$ & $222(89.2)$ & 1 & 0.33 \\
\hline Yes & $238(13.1)$ & $27(10.8)$ & $1.23(0.81-1.88)$ & \\
\hline \multicolumn{5}{|l|}{ Atrial fibrillation, $n(\%)$} \\
\hline No & $1,334(73.2)$ & $199(79.9)$ & 1 & 0.02 \\
\hline Yes & $489(26.8)$ & $50(20.1)$ & $1.46(1.05-2.02)$ & \\
\hline Number of comorbidities, $n(\%)$ & & & $1.18(1.02-1.37)$ & $0.02^{\dagger}$ \\
\hline 0 & $638(35.0)$ & $116(46.6)$ & & \\
\hline 1 & $652(35.8)$ & $64(25.7)$ & & \\
\hline 2 & $400(22.0)$ & $53(21.3)$ & & \\
\hline 3 & $118(6.5)$ & $15(6.0)$ & & \\
\hline 4 & $15(0.8)$ & $1(0.4)$ & & \\
\hline \multicolumn{5}{|c|}{$\begin{array}{l}\S \text { Probability modeled is the probability to be assigned to the HD cohort. } \\
\text { A } 10 \text {-unit increase in age was considered. } \\
\text { Test for trend. } \\
\text { HD, hemodialysis; PD, peritoneal dialysis. }\end{array}$} \\
\hline
\end{tabular}

considered, except for atrial fibrillation, which was more prevalent in HD patients (OR 1.46, 95\% CI 1.05-2.02, $p=$ $0.024)$. HD patients had a greater number of comorbidities than those on PD (OR 1.18, 95\% CI 1.02-1.37, $p=0.025$ ). Fifty-two patients $(2.5 \%)$ received an ICD for primary or secondary SD prevention, and 10 of them (19.2\%) were PD patients. The median duration of follow-up was 1.76 years (IQR 0.79-3.35 years) in HD patients and 1.94 years (IQR $0.84-3.34$ years) in those on $\mathrm{PD}$ (C98\% of the potential time of follow-up in HD patients and 99\% in PD patients). The observed deaths were 688: 626 of 1,823 (34.3\%) in HD patients and 62 of 249 (24.9\%) in PD patients. A sum of 150 of 626 (24.0\%) patients on $\mathrm{HD}$, and 22 of 62 (35.5\%) PD patients died from cardiovascular causes (Table 2).

\section{Total Mortality}

The median survival was 3.16 (95\% CI 2.82-3.60) years in HD patients and 5.33 (95\% CI 4.05-6.04) years in patients on PD. Considering only patients alive at 6 months after starting dialysis (early mortality, 13.4\% [95\% CI $11.3-15.8 \%$ ] in HD and $4.5 \%$ [95\% CI 2.2-9.2\%] in PD), the prognosis was still better in PD patients (3.88 [95\% CI $3.55-4.36$ ] vs. 5.33 [95\% CI 4.59-6.92] years). Figure 1 shows the survival curves of the 2 populations; at the start of dialysis, the survival of PD patients was higher than that of $\mathrm{HD}$ patients $\left(\mathrm{HR}_{\text {[at dialysis start] }} 0.41,95 \%\right.$ CI $0.29-$ $0.60, p$ value $<0.001)$. However, this advantage tended to decrease with time $\left(\mathrm{HR}_{\text {[linear interaction with time] }} 1.21,95 \% \mathrm{CI}\right.$ $1.11-1.31$, $p$ value $<0.001$; Fig. $2 a$ ). Because the likelihood 
Fig. 1. Survival curves of patients on hemodialysis (HD) and peritoneal dialysis (PD).

Table 2. Follow-up and events

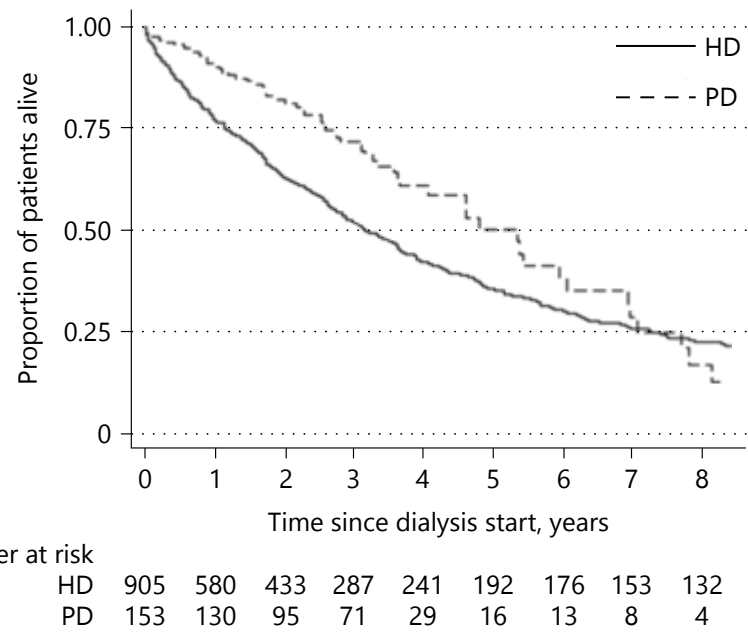

\begin{tabular}{lcc}
\hline & Patients & \\
\cline { 2 - 3 } & HD & PD \\
\hline Sample size, $n$ & 1,823 & 249 \\
Number of deaths, $n$ (\%) & $626(34.3)$ & $62(24.9)$ \\
Accrual period & January 1, 2010 to January 31, 2013 \\
Closing date & January 31,2014 & \\
Length of follow-up, years & & 1.94 \\
Median & 1.76 & $0.84-3.34$ \\
IQR & $0.79-3.35$ & \\
Completeness of & & 99 \\
$\quad$ follow-up (C index), \% & 98 & $18(31.6)$ \\
Causes of death, $n$ (\%) & $153(26.0)$ & $11(19.3)$ \\
Cachexia* & $134(22.8)$ & $13(22.8)$ \\
Sepsis* & $71(12.1)$ & $3(5.3)$ \\
Sudden death* & $66(11.2)$ & $8(14.0)$ \\
Neoplasia* & $40(6.8)$ & $1(1.8)$ \\
Heart failure* & $39(6.6)$ & $1(1.8)$ \\
Stroke* & $48(8.2)$ & 0 \\
Vascular disease* & $18(3.1)$ & $1(1.8)$ \\
Hemorrhage* & & 0 \\
Chronic pulmonary & $13(2.2)$ & $1(1.8)$ \\
$\quad$ disease* & $4(0.7)$ & $5(8.1)$ \\
Dementia* & $2(0.3)$ & \\
Liver cirrhosis* & $38(6.1)$ & \\
Unknown & & \\
\hline
\end{tabular}

$\mathrm{HD}$, hemodialysis; PD, peritoneal dialysis.

* Percentage was calculated by excluding unknown cause. 


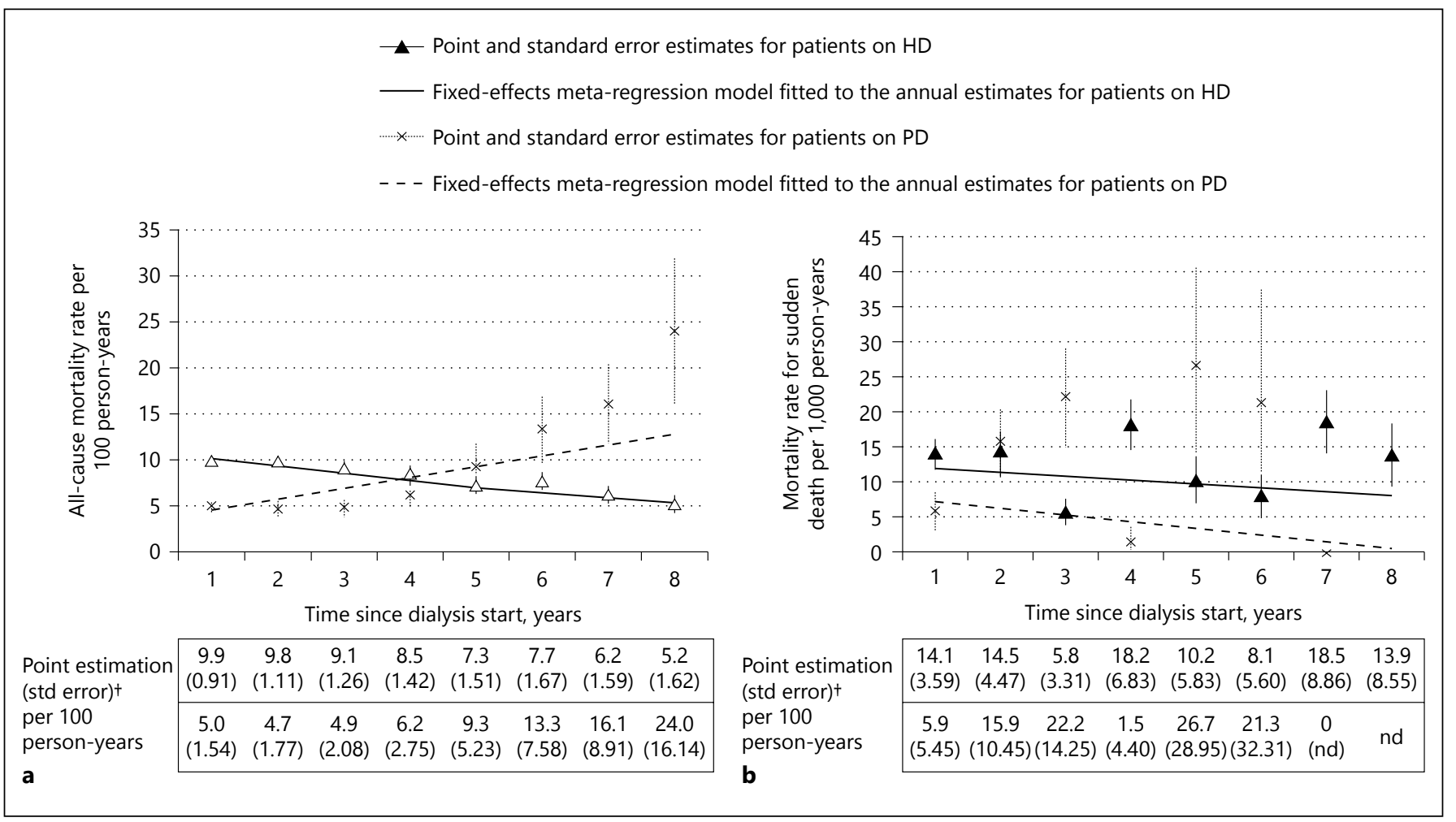

Fig. 2. a, b Annual mortality rates of patients on hemodialysis (HD) and peritoneal dialysis (PD). ${ }^{\dagger}$ First row: annual estimates for patients on HD. Second row: annual estimates for patients on PD. Point and standard error estimates for patients on HD. Fixed-ef-

ratio test was not significant $\left(\chi^{2}=3.64 ; \mathrm{df}=1 ; p\right.$ value $=$ 0.06 ), the quadratic term was removed from the regression model. The restricted mean at 8 years showed a weaker advantage in comparison to median survival (3.87 [95\% CI 3.65-4.08] years in HD patients and 4.81 [95\% CI 4.27-5.36] years in PD patients; $p$ value $<0.001$ ).

The analysis relative to the influence of each comorbidity on total mortality in the 2 cohorts of patients is shown in Table 3. In both populations, factors associated with an increased risk of mortality were older age, LVEF $\leq 35 \%$, and the presence of ischemic heart disease, diabetes mellitus, previous strokes, and atrial fibrillation. The HR for individual comorbidity was higher in patients on $\mathrm{PD}$, and the interaction test for dialysis treatment (HD vs. PD) was significant for ischemic heart disease ( $p$ value $<0.001$ ), diabetes mellitus ( $p$ value $=0.02$ ), and atrial fibrillation $(p$ value $=0.01)$.

Multivariable analysis confirmed that PD patients had a lower risk of death than HD patients (HR 0.13, 95\% CI $0.05-0.33, p$ value $<0.001)$ at the start of dialysis, and that the difference was significantly reduced with increasing fects meta-regression model fitted to the annual estimates for patients on HD. Point and standard error estimates for patients on PD. Fixed-effects meta-regression model fitted to the annual estimates for patients on PD.

time $\left(\mathrm{HR}_{[\text {linear interaction with time] }} 1.33,95 \% \mathrm{CI} 1.20-1.46, p\right.$ value $<0.001)$. The independent association between risk of death and older age, ischemic heart disease, LVEF $\leq 35 \%$, diabetes mellitus, previous stroke, and atrial fibrillation was also confirmed. An interaction effect between dialysis modality and comorbidities was still present for ischemic heart disease $(p$ value $=0.01)$ and atrial fibrillation $(p$ value $=0.03$; Table 4).

\section{Sudden Death}

During follow-up, 84 SDs occurred. SD, excluding unknown causes, accounted for $22.8 \%$ (13 of 57) of causes of death in PD patients and $12.1 \%$ (71 of 588) in those on HD. There was no significant difference in the incidence of SD among patients on HD compared to $\mathrm{PD}$ patients, although the latter showed an increased risk of $23.0 \%\left(\mathrm{HR}_{\text {cpRisk }} 1.23,95 \%\right.$ CI $0.68-2.23$, $p$ value $=0.49$; Fig. 3). The time from starting dialysis treatment did not significantly affect the $\mathrm{HR}_{\text {cpRisk }}$ and the incidence of $\mathrm{SD}$ in either group ( $p$ value $[$ linear interaction with time] $=0.19$; Fig. 2b). 
Table 3. Univariate Cox analysis results on death risk for any cause in the 2 cohorts

\begin{tabular}{|c|c|c|c|c|c|c|c|}
\hline Variable & Category & HR & $95 \% \mathrm{CI}$ & $p$ value & HR & $95 \% \mathrm{CI}$ & $p$ value \\
\hline Gender & $\begin{array}{l}\text { Female } \\
\text { Male } \\
\text { Test for interaction }\end{array}$ & $\begin{array}{l}1 \\
0.93 \\
Z:-2.02 ; p \text { value: } 0.04\end{array}$ & $0.79-1.10$ & 0.40 & $\begin{array}{l}1 \\
1.75\end{array}$ & $0.99-3.07$ & 0.50 \\
\hline $\begin{array}{l}\text { Left ventricular } \\
\text { ejection fraction }\end{array}$ & $\begin{array}{l}<35 \% \\
>35 \% \\
\text { Test for interaction }\end{array}$ & $\begin{array}{l}1 \\
0.48 \\
Z: 0.40 ; p \text { value: } 0.59\end{array}$ & $0.38-0.62$ & $<0.001$ & $\begin{array}{l}1 \\
0.36\end{array}$ & $0.19-0.67$ & $<0.01$ \\
\hline Diabetes mellitus & $\begin{array}{l}\text { No } \\
\text { Yes } \\
\text { Test for interaction }\end{array}$ & $\begin{array}{l}1 \\
1.29 \\
Z:-2.35 ; p \text { value: } 0.02\end{array}$ & $1.09-1.54$ & $<0.01$ & $\begin{array}{l}1 \\
2.70\end{array}$ & $1.61-4.54$ & $<0.001$ \\
\hline Previous ischemic stroke & $\begin{array}{l}\text { No } \\
\text { Yes } \\
\text { Test for interaction }\end{array}$ & $\begin{array}{l}1 \\
1.47 \\
Z:-1.71 ; p \text { value: } 0.09\end{array}$ & $1.20-1.80$ & $<0.001$ & $\begin{array}{l}1 \\
2.58\end{array}$ & $1.34-4.98$ & $<0.01$ \\
\hline Atrial fibrillation & $\begin{array}{l}\text { No } \\
\text { Yes } \\
\text { Test for interaction }\end{array}$ & $\begin{array}{l}1 \\
1.49 \\
Z:-2.66 ; p \text { value: } 0.01\end{array}$ & $1.26-1.76$ & $<0.001$ & $\begin{array}{l}1 \\
4.20\end{array}$ & $2.44-7.24$ & $<0.001$ \\
\hline
\end{tabular}

${ }^{\circ}$ A 10 -unit increase in age was considered.

$\mathrm{HD}$, hemodialysis; PD, peritoneal dialysis.

Among HD patients who died suddenly, 58 of 71 (81.7\%) had an LVEF $>35 \%$, while among PD patients who suffered a SD, those with preserved LVEF were 7 of $13(53.8 \%$; $p$ value $=0.03)$. A total of 22 of $48(45.8 \%) \mathrm{HD}$ patients, in whom the timing of death with respect to the HD session could be established, died during the first inter-dialytic interval and 18 of 48 (37.5\%) during the last long inter-dialytic interval of the week.

The analysis of the influence of each comorbidity on SD risk in the 2 cohorts of patients is shown in Table 5. Variables associated with a higher incidence of SD in HD patients were older age, presence of LVEF $\leq 35 \%$, ischemic heart disease, and diabetes mellitus, while in patients on PD, reduced LVEF, previous strokes, and slightly ischemic heart disease were associated with SD. The interaction test for dialysis treatment (HD versus $\mathrm{PD}$ ) was not significant for any of the comorbidities considered.
Multivariable analysis showed that factors significantly associated with SD were older age, presence of LVEF $\leq 35 \%$, ischemic heart disease, and also diabetes mellitus. The difference in SD incidence was not significantly influenced by dialysis modality $\left(\mathrm{HR}_{\mathrm{cpRisk}} 1.24,95 \%\right.$ CI $0.68-$ $2.26, p$ value $=0.49$; Table 6 )

\section{Discussion}

This study shows that, in an ESRD population, survival is higher in $\mathrm{PD}$ than in HD patients. SD incidence, however, is not different in the 2 cohorts of patients and $\mathrm{SD}$, when considering all causes of death, is relatively more frequent in $\mathrm{PD}$ than in HD patients.

In the literature, data on mortality risk comparing $\mathrm{PD}$ with HD are not univocal [11,12, 16-19]. It is likely that patients reaching ESRD due to acute renal failure or hav- 
Table 4. Multivariate Cox analysis results on death risk for any cause

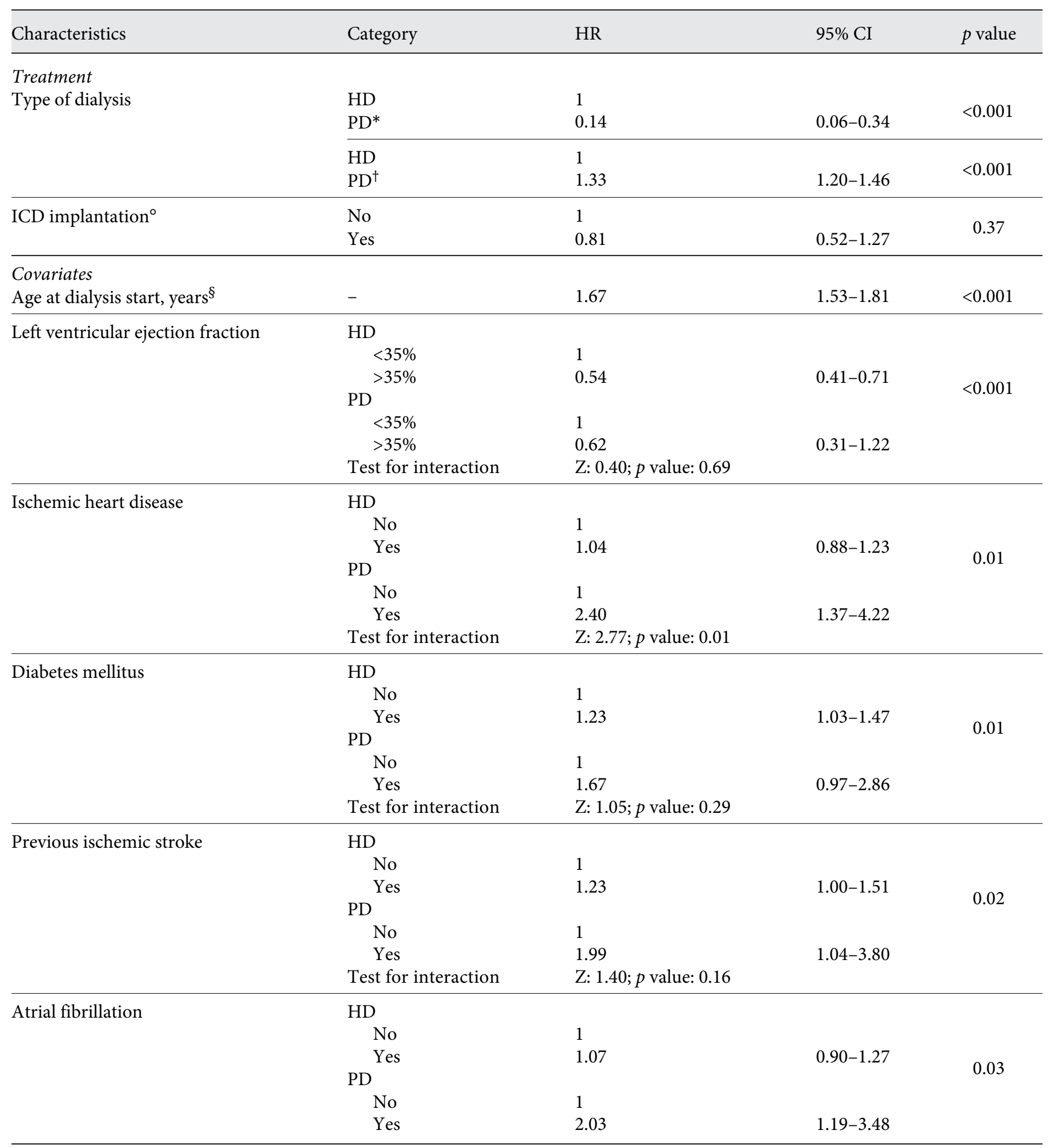

${ }^{*}$ HR at dialysis start; ${ }^{\dagger}$ linear type of dialysis-by-time interaction; ${ }^{\circ}$ time-varying treatment; ${ }^{\S}$ a 10 -unit increase in age. 
Fig. 3. Cumulative incidence of sudden death and death due to other causes of patients on hemodialysis (HD) and peritoneal dialysis (PD).

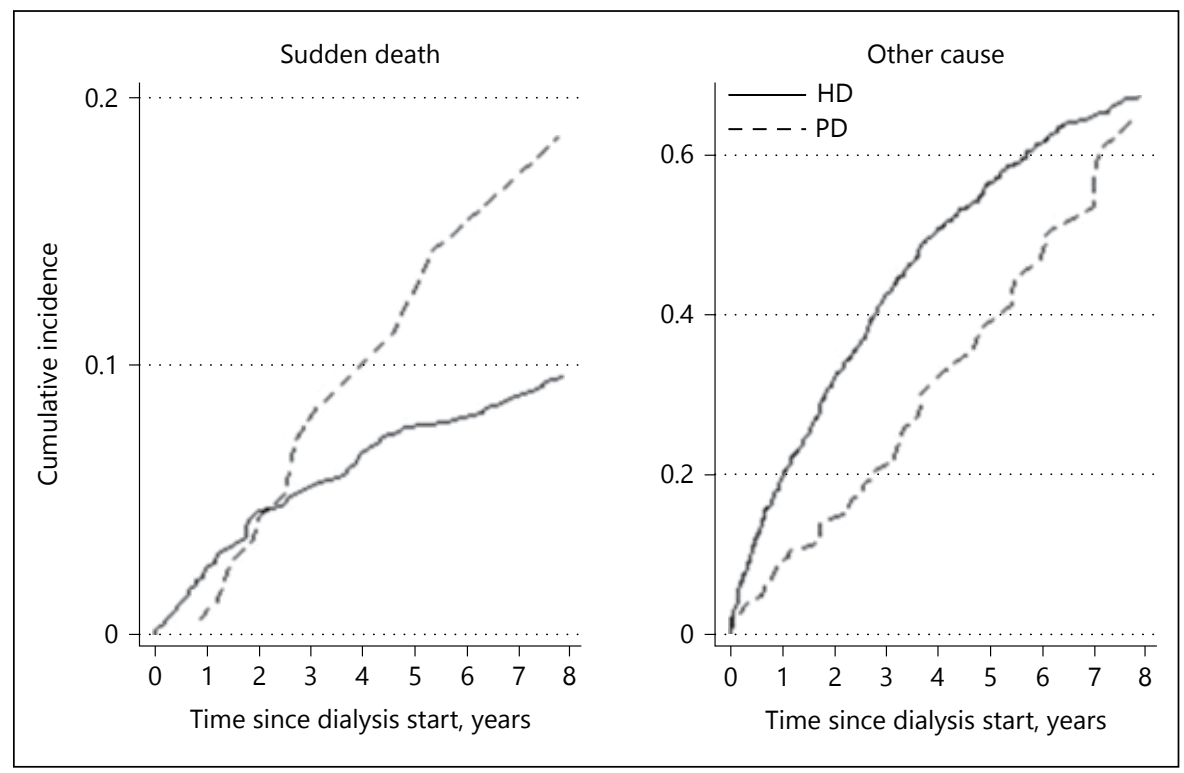

ing worse clinical conditions are preferentially placed on HD. The frailty of these patients may increase early mortality after starting renal replacement therapy [20]; however, in our study, the survival of PD patients still remains higher compared to HD patients, even after eliminating early mortality from the analysis. Nevertheless, this advantage decreases over time from starting dialysis therapy. Moreover, in PD patients, the presence of each comorbidity determines an increase in the risk of death for any cause by $2-3$ times compared to HD patients, and this finding is particularly evident for ischemic heart disease and atrial fibrillation. This result confirms what had already been observed by other authors [19,21]. In ESRD patients, the presence of diabetes mellitus and poor glycemic control are often associated with several clinical complications and with an increase of mortality, particularly in PD patients [22-24]. In addition, in the tissues of PD patients, diabetic or not, there is a great deposition of advanced glycation end products that predispose to the metabolic syndrome [25], a condition associated with an increased risk of cardiovascular mortality in this population [26]. Several studies demonstrated that, in PD patients, accelerated atherosclerosis processes are actively present and suggest that atherosclerosis risk is even higher in PD than in HD patients [27-29].

An increased risk of death in HD patients with atrial fibrillation has been described [30], while there are no data on atrial fibrillation and mortality in PD patients. The HD session may trigger episodes of atrial fibrillation, particularly of the paroxysmal type $[31,32]$. It is possible that, in our study population, PD patients had more frequent forms of permanent atrial fibrillation and that this may partly justify the higher risk of death associated with the arrhythmia compared to HD patients. Non-paroxysmal atrial fibrillation, in fact, is usually associated with the presence of cardiac disease and with a highly significant increase in thromboembolism and death [33]. Moreover, HD patients meet their nephrologist 3 times a week, while PD patients perform only monthly clinical checks. This could create a less effective clinical monitoring of cardiovascular disease in the latter population.

In our population, the incidence of SD was independent of dialysis modality and even slightly higher in subjects undergoing PD. Data also show that, among all causes of death, SD was about twice as frequent in PD as in HD patients. The reported SD incidence is 49 per 1,000 patients per year in the HD population and 36 per 1,000 patients per year in the population on PD [1]. The factors that lead PD patients to die suddenly could somewhat differ from those that induce SD in HD patients. A previous study linked SD in PD patients with reduced LVEF and elevated plasma levels of pro-BNP and troponin $\mathrm{T}$, suggesting an important role of heart failure and ischemic heart disease as factors associated with increased sudden mortality [34]. In our population, among patients who suffered SD, prevalence of subjects with LVEF $\leq 35 \%$ was higher in $\mathrm{PD}$ compared to HD patients. This finding suggests that the presence of severe cardiac disease could play an important role 


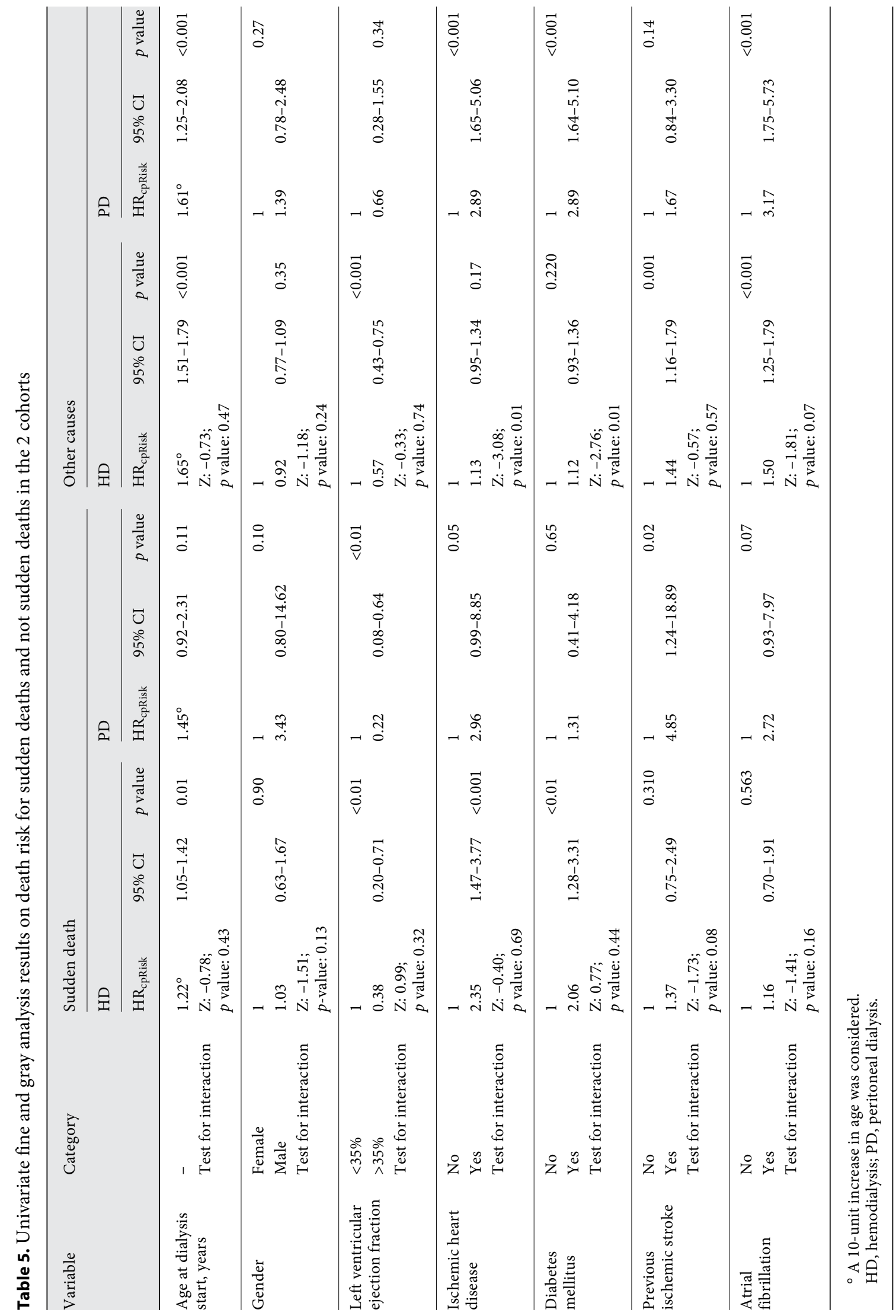


Table 6. Multivariate fine and gray analysis results on death risk for sudden deaths

\begin{tabular}{|c|c|c|c|}
\hline Variable & $\mathrm{HR}_{\mathrm{cpRisk}}$ & $95 \%$ CI & $p$ value \\
\hline \multicolumn{4}{|l|}{ Treatment } \\
\hline \multicolumn{4}{|l|}{ Type of dialysis } \\
\hline HD & 1 & & \\
\hline $\mathrm{PD}$ & 1.24 & $0.68-2.26$ & 0.49 \\
\hline \multicolumn{4}{|l|}{ ICD implantation $^{\circ}$} \\
\hline No & 1 & & 0.72 \\
\hline Yes & 1.21 & $0.43-3.40$ & \\
\hline \multicolumn{4}{|l|}{ Covariates } \\
\hline Age at dialysis start, years ${ }^{\S}$ & $1.20^{\circ}$ & $1.01-1.42$ & 0.03 \\
\hline \multicolumn{4}{|c|}{ Left ventricular ejection fraction } \\
\hline$<35 \%$ & 1 & & \multirow{2}{*}{0.04} \\
\hline$>35 \%$ & 0.51 & $0.26-0.99$ & \\
\hline \multicolumn{4}{|l|}{ Ischemic heart disease } \\
\hline No & 1 & & \multirow{2}{*}{0.01} \\
\hline Yes & 1.80 & $1.13-2.87$ & \\
\hline \multicolumn{4}{|l|}{ Diabetes mellitus } \\
\hline No & 1 & & \multirow{2}{*}{0.06} \\
\hline Yes & 1.55 & $0.98-2.46$ & \\
\hline \multicolumn{4}{|l|}{ Previous ischemic stroke } \\
\hline No & 1 & & \multirow{2}{*}{0.26} \\
\hline Yes & 1.38 & $0.79-2.40$ & \\
\hline \multicolumn{4}{|l|}{ Atrial fibrillation } \\
\hline No & 1 & & \multirow{2}{*}{0.97} \\
\hline Yes & 0.99 & $0.60-1.63$ & \\
\hline
\end{tabular}

${ }^{\circ}$ Time-varying treatment; ${ }^{\S}$ a 10 -unit increase in age was considered.

in determining SD in the PD population, while in $\mathrm{HD}$ patients factors that are most closely related to dialysis modality may be relevant. In an Australian population, a daily variation in the pattern of cardiac deaths was observed in HD patients receiving 3 dialysis sessions per week, but not in PD patients [35]. SD occurs more frequently during the long inter-dialytic interval or after the first HD session of the week [5, 6], and in $50 \mathrm{HD}$ patients having an implanted cardiac monitor, the risk of SD and significant arrhythmias was greatest during the long inter-dialytic interval [36]. Moreover, HD sessions themselves can cause cardiac arrest and lower concentrations of potassium and calcium in the dialysate are associated with a higher incidence of cardiac intradialytic arrest [37, 38]. In agreement with these data, we observed that the majority of SDs of our HD patients occurred just before or just after the first HD session of the week. All this evidence partly justifies the high SD incidence in HD patients, even in those with preserved LVEF, but it is not clear as to why sudden mortality is also high in PD patients. The effects of intra-dialytic modifications of the electrolytes on the cardiac action potential have been widely investigated in HD patients [39-41], while very few studies have been done regarding possible electrolyte disturbances in PD patients and their potential arrhythmogenic effects. However, both HD and PD populations show an alteration of potassium handling, even if the electrolyte plasma fluctuations differ in relation to different dialysis modalities. Some authors have shown an excess of mortality in PD patients associated with serum potassium disturbances. Torlén et al. [42] described that PD patients are more likely to have serum potassium $<4$ $\mathrm{mEq} / \mathrm{L}$ compared to $\mathrm{HD}$ patients and that there is a $\mathrm{U}$ shaped relationship between time-averaged serum potassium and PD patients' mortality. Recently, it was reported that both time-averaged serum potassium and its fluctuation contribute to the high death risk in PD patients [43]. These studies allow us to hypothesize that electrolyte abnormalities could increase the risk of death also in this population.

Our study has some limitations being a retrospective study. A treatment selection bias was present, because the nephrologist was free to choose the dialysis modality for each patient. Moreover, data on plasma concentrations of electrolytes in the 2 study populations are lacking. However, our data show that SD is an important clinical problem even in the PD population and not only in HD patients and strongly suggest the need to undertake studies with the aim of understanding the mechanisms behind this type of death in patients undergoing PD.

\section{Disclosure Statement}

The authors have declared that no conflict of interest exists.

References

1 United States Renal Data System: 2015 USRDS Annual Data Report: Epidemiology of Kidney Disease in the United States. Bethesda, National Institutes of Health, National Institute of Diabetes and Digestive and Kidney Diseases, 2015.

2 Bigger JT Jr, Fleiss JL, Kleiger R, Miller JP, Rolnitzky LM: The relationships among ventricular arrhythmias, left ventricular dysfunction, and mortality in the 2 years after myocardial infarction. Circulation 1984;69:250 258.
86

Blood Purif 2017;44:77-88

DOI: $10.1159 / 000464347$
Genovesi et al. 
3 Solomon SD, Anavekar N, Skali H, McMurray JJ, Swedberg K, Yusuf S, Granger CB, Michelson EL, Wang D, Pocock S, Pfeffer MA; Candesartan in Heart Failure Reduction in Mortality (CHARM) Investigators: Influence of ejection fraction on cardiovascular outcomes in a broad spectrum of heart failure patients. Circulation 2005;112:37383744.

4 Solomon SD, Zelenkofske S, McMurray JJ, Finn PV, Velazquez E, Ertl G, Harsanyi A, Rouleau JL, Maggioni A, Kober L, White H, Van de Werf F, Pieper K, Califf RM, Pfeffer MA; Valsartan in Acute Myocardial Infarction Trial (VALIANT) Investigators: Sudden death in patients with myocardial infarction and left ventricular dysfunction, heart failure, or both. N Engl J Med 2005;352:25812588.

5 Bleyer AJ, Russell GB, Satko SG: Sudden and cardiac death rates in hemodialysis patients. Kidney Int 1999;55:1553-1559.

6 Genovesi S, Valsecchi MG, Rossi E, Pogliani D, Acquistapace I, De Cristofaro V, Stella A, Vincenti A: Sudden death and associated factors in a historical cohort of chronic haemodialysis patients. Nephrol Dial Transplant 2009;24:2529-2536.

7 Fenton SS, Schaubel DE, Desmeules M, Morrison HI, Mao Y, Copleston P, Jeffery JR, Kjellstrand CM: Hemodialysis versus peritoneal dialysis: a comparison of adjusted mortality rates. Am J Kidney Dis 1997;30:334342.

8 McDonald SP, Marshall MR, Johnson DW, Polkinghorne KR: Relationship between dialysis modality and mortality. J Am Soc Nephrol 2009;20:155-163.

9 Heaf JG, Løkkegaard H, Madsen M: Initial survival advantage of peritoneal dialysis relative to haemodialysis. Nephrol Dial Transplant 2002;17:112-117.

10 Liem YS, Wong JB, Hunink MG, de Charro FT, Winkelmayer WC: Comparison of hemodialysis and peritoneal dialysis survival in The Netherlands. Kidney Int 2007;71:153158.

11 Kumar VA, Sidell MA, Jones JP, Vonesh EF: Survival of propensity matched incident peritoneal and hemodialysis patients in a United States health care system. Kidney Int 2014;86: 1016-1022.

12 Lukowsky LR, Mehrotra R, Kheifets L, Arah OA, Nissenson AR, Kalantar-Zadeh K: Comparing mortality of peritoneal and hemodialysis patients in the first 2 years of dialysis therapy: a marginal structural model analysis. Clin J Am Soc Nephrol 2013;8:619-628.

13 Cleves M, Gutierrez RG, Gould W, Marchenko Y: An Introduction to Survival Analysis Using Stata. Texas, Stata Press, 2010.

14 Schemper M, Smith TL: A note on quantifying follow-up in studies of failure time. Control Clin Trials 1996;17:343-346.

15 Clark TG, Altman DG, De Stavola BL: Quantification of the completeness of follow-up. Lancet 2002;359:1309-1310.
16 Jaar BG, Coresh J, Plantinga LC, Fink NE, Klag MJ, Levey AS, Levin NW, Sadler JH, Kliger A, Powe NR: Comparing the risk for death with peritoneal dialysis and hemodialysis in a national cohort of patients with chronic kidney disease. Ann Intern Med 2005;143: 174-183.

17 Mehrotra R, Chiu YW, Kalantar-Zadeh K, Bargman J, Vonesh E: Similar outcomes with hemodialysis and peritoneal dialysis in patients with end-stage renal disease. Arch Intern Med 2011;171:110-118.

18 Waldum-Grevbo B, Leivestad T, Reisæter AV, Os I: Impact of initial dialysis modality on mortality: a propensity-matched study. BMC Nephrol 2015;16:179.

19 Yang F, Khin LW, Lau T, Chua HR, Vathsala A, Lee E, Luo N: Hemodialysis versus peritoneal dialysis: a comparison of survival outcomes in South-East Asian patients with endstage renal disease. PLoS One 2015; 10:e0140195.

20 Murphy SW, Foley RN, Barrett BJ, Kent GM, Morgan J, Barré P, Campbell P, Fine A, Goldstein MB, Handa SP, Jindal KK, Levin A, Mandin H, Muirhead N, Richardson RM, Parfrey PS: Comparative mortality of hemodialysis and peritoneal dialysis in Canada. Kidney Int 2000;57:1720-1726.

21 Weinhandl ED, Foley RN, Gilbertson DT, Arneson TJ, Snyder JJ, Collins AJ: Propensity-matched mortality comparison of incident hemodialysis and peritoneal dialysis patients. J Am Soc Nephrol 2010;21:499506.

22 Park JI, Bae E, Kim YL, Kang SW, Yang CW, Kim NH, Lee JP, Kim DK, Joo KW, Kim YS, Lee H: Glycemic control and mortality in diabetic patients undergoing dialysis focusing on the effects of age and dialysis type: a prospective cohort study in Korea. PLoS One 2015; 10:e0136085.

23 Duong U, Mehrotra R, Molnar MZ, Noori N, Kovesdy CP, Nissenson AR, KalantarZadeh K: Glycemic control and survival in peritoneal dialysis patients with diabetes mellitus. Clin J Am Soc Nephrol 2011;6: 1041-1048.

24 Yi C, Guo Q, Lin J, Huang F, Yu X, Yang X: Clinical outcomes of remote peritoneal dialysis patients: a retrospective cohort study from a single center in China. Blood Purif 2016;41: 100-107.

25 McIntyre NJ, Chesterton LJ, John SG, Jefferies HJ, Burton JO, Taal MW, Fluck RJ, McIntyre CW: Tissue-advanced glycation end product concentration in dialysis patients. Clin J Am Soc Nephrol 2010;5:51-55.

26 Li PK, Kwan BC, Ko GT, Chow KM, Leung CB, Szeto CC: Treatment of metabolic syndrome in peritoneal dialysis patients. Perit Dial Int 2009;29:S149-S152.

27 Ozdemir FN, Güz G, Sezer S, Arat Z, Turan M, Haberal M: Atherosclerosis risk is higher in continuous ambulatory peritoneal dialysis patients than in hemodialysis patients. Artif Organs 2001;25:448-452.
28 Harmankaya O, Akalin N, Akay H, Okuturlar Y, Erturk K, Kaptanogullari H, Kocoglu H: Comparison of risk factors for cardiovascular disease in hemodialysis and peritoneal dialysis patients. Clinics (Sao Paulo) 2015;70:601605.

29 Wang IK, Liang WM, Lin CL, Liu YL, Chang CT, Yen TH, Huang CC, Sung FC: Impact of dialysis modality on the survival of patients with end-stage renal disease and prior stroke. Int Urol Nephrol 2016;48:139147.

30 Genovesi S, Vincenti A, Rossi E, Pogliani D, Acquistapace I, Stella A, Valsecchi MG: Atrial fibrillation and morbidity and mortality in a cohort of long-term hemodialysis patients. Am J Kidney Dis 2008;2:255-262.

31 Vincenti A, Passini E, Fabbrini P, Luise MC, Severi S, Genovesi S: Recurrent intradialytic paroxysmal atrial fibrillation: hypotheses on onset mechanisms based on clinical data and computational analysis. Europace 2014;16: 396-404.

32 Buiten MS, de Bie MK, Rotmans JI, Gabreëls BA, van Dorp W, Wolterbeek R, Trines SA Schalij MJ, Jukema JW, Rabelink TJ, van Erven L: The dialysis procedure as a trigger for atrial fibrillation: new insights in the development of atrial fibrillation in dialysis patients. Heart 2014;100:685-690.

33 Ganesan AN, Chew DP, Hartshorne T, Selvanayagam JB, Aylward $\mathrm{PE}$, Sanders $\mathrm{P}$, McGavigan AD: The impact of atrial fibrillation type on the risk of thromboembolism, mortality, and bleeding: a systematic review and meta-analysis. Eur Heart J 2016;37: 1591-1602.

34 Wang AY, Lam CW, Chan IH, Wang M, Lui SF, Sanderson JE: Sudden cardiac death in end-stage renal disease patients: a 5-year prospective analysis. Hypertension 2010;56:210216

35 Krishnasamy R, Badve SV, Hawley CM, McDonald SP, Boudville N, Brown FG, Polkinghorne KR, Bannister KM, Wiggins KJ, Clayton $\mathrm{P}$, Johnson DW: Daily variation in death in patients treated by long-term dialysis: comparison of in-center hemodialysis to peritoneal and home hemodialysis. Am J Kidney Dis 2013;61:96-103.

36 Wong MC, Kalman JM, Pedagogos E, Toussaint N, Vohra JK, Sparks PB, Sanders P, Kistler PM, Halloran K, Lee G, Joseph SA, Morton JB: Temporal distribution of arrhythmic events in chronic kidney disease: highest incidence in the long interdialytic period. Heart Rhythm 2015;12:20472055.

37 Pun PH, Lehrich RW, Honeycutt EF, Herzog CA, Middleton JP: Modifiable risk factors associated with sudden cardiac arrest within hemodialysis clinics. Kidney Int 2011;79:218227.

38 Pun PH, Horton JR, Middleton JP: Dialysate calcium concentration and the risk of sudden cardiac arrest in hemodialysis patients. Clin J Am Soc Nephrol 2013;8:797-803. 
39 Severi S, Grandi E, Pes C, Badiali F, Grandi F, Santoro A: Calcium and potassium changes during haemodialysis alter ventricular repolarization duration: in vivo and in silico analysis. Nephrol Dial Transplant 2008;23:1378-1386.

40 Näppi SE, Virtanen VK, Saha HH, Mustonen JT, Pasternack AI: QTc dispersion increases during hemodialysis with low-calcium dialysate. Kidney Int 2000;57:2117-2122.
41 Genovesi S, Dossi C, Viganò MR, Galbiati E, Prolo F, Stella A, Stramba-Badiale M: Electrolyte concentration during haemodialysis and QT interval prolongation in uraemic patients. Europace 2008;10:771-777.

42 Torlén K, Kalantar-Zadeh K, Molnar MZ, Vashistha T, Mehrotra R: Serum potassium and cause-specific mortality in a large peritoneal dialysis cohort. Clin J Am Soc Nephrol 2012;7:1272-1284.
43 Li SH, Xie JT, Long HB, Zhang J, Zhou WD, Niu HX, Tang X, Feng ZL, Ye ZM, Zuo YY, Fu L, Wen F, Wang LP, Wang WJ, Shi $\mathrm{W}$ : Time-averaged serum potassium levels and its fluctuation associate with 5-year survival of peritoneal dialysis patients: two-center based study. Sci Rep 2015;5: 15743. 